\title{
Perfusion CT can predict the response to chemoradiation therapy and survival in esophageal squamous cell carcinoma: Initial clinical results
}

\author{
KOICHI HAYANO ${ }^{1}$, SHINICHI OKAZUMI ${ }^{1}$, KIYOHIKO SHUTO ${ }^{1}$, HISAHIRO MATSUBARA ${ }^{1}$, \\ HIDEAKI SHIMADA ${ }^{1}$, YOSHIHIRO NABEYA ${ }^{1}$, TOSHIKI KAZAMA ${ }^{2}$, \\ NORIYUKI YANAGAWA ${ }^{3}$ and TAKENORI OCHIAI ${ }^{1}$ \\ ${ }^{1}$ Department of Frontier Surgery, Chiba University Graduate School of Medicine; ${ }^{2}$ Department of Radiology, \\ Chiba University Graduate School of Medicine; ${ }^{3}$ Division of Radiology, Chiba University Hospital \\ 1-8-1 Inohana, Chuo-ku, Chiba 260-8677, Japan
}

Received May 11, 2007; Accepted July 9, 2007

\begin{abstract}
The ability to predict the response to chemoradiation therapy (CRT) by contrast-enhanced CT would be valuable for managing esophageal squamous cell carcinoma. The purpose of this study was to evaluate the usefulness of Perfusion CT to predict the response to $\mathrm{CRT}$ in patients with esophageal squamous cell carcinoma. Thirty-one consecutive patients with esophageal squamous cell carcinoma underwent Perfusion CT before CRT. We retrospectively investigated the correlations between Perfusion parameters and the response to CRT. Clinicopathological markers and blood flow were compared in terms of survival. There were 21 clinical responders and 10 non-responders. Clinical responders showed significantly higher pre-CRT blood flow ( $\mathrm{P}=0.0004)$, significantly higher pre-CRT blood volume $(\mathrm{P}=0.03)$ and a significantly shorter pre-CRT mean transit time $(\mathrm{P}=0.002)$ than non-responders. For pre-CRT blood flow, accuracy was $90.3 \%$ for detection of clinical responders when the cut-off point was set at $50 \mathrm{ml} /$ $100 \mathrm{~g} / \mathrm{min}$. Patients with high blood flow tumors survived significantly longer than those with low blood flow tumors $(\mathrm{P}=0.006)$. Multivariate analysis identified blood flow as a significant independent prognostic factor $(\mathrm{P}=0.01)$. Therefore, Perfusion CT may help to identify patients with advanced esophageal squamous cell carcinoma who will benefit from CRT.
\end{abstract}

\section{Introduction}

Despite improvements in surgical techniques, a rapid fatal recurrence is common in patients with locally advanced

Correspondence to: Dr Koichi Hayano, Department of Frontier Surgery, Chiba University Graduate School of Medicine, 1-8-1 Inohana, Chuo-ku, Chiba 260-8677, Japan

E-mail: k-hayano@graduate.chiba-u.jp

Key words: perfusion CT, esophageal cancer, angiogenesis, chemoradiation therapy esophageal cancer. Because surgical resection alone rarely results in long-term survival, efforts are now being focused on combined multimodality treatment in an attempt to improve the operative resectability and the outcome. Chemoradiation therapy (CRT) is one of the most commonly used modalities for esophageal cancer. CRT followed by esophagectomy has become a widespread treatment protocol since several favorable pilot studies were reported (1-5). In our department, CRT using cisplatin and 5-fluorouracil has been used since 1991 and non-responders showed a significantly lower 5-year survival rate than responders (6). It would therefore be useful to predict the response to CRT so that non-responders can avoid the side effects associated with intensive therapeutic regimens. However, there are still no methods for predicting which tumors will respond to CRT.

Perfusion CT is a new technology that allows the measurement of tumor vascular physiology. Both tissue and vascular enhancement by contrast materials can be measured and traced over time and mathematic models for contrast material exchange have been developed to quantify tissue blood flow, blood volume, mean transit time and capillary permeability fraction (7-14). Morphologic and physiologic changes in tumor blood vessels may have a major effect on the treatment of various solid tumors, particularly regarding drug delivery and the effectiveness of radiation therapy (15-17). However, to our knowledge, no data concerning the relationship between the Perfusion CT measurements and the response to CRT in esophageal cancer have yet been reported. Therefore, we analyzed the Perfusion CT measurements in patients with primary esophageal squamous cell carcinoma, and assessed whether Perfusion CT could be used to predict the response to CRT in esophageal squamous cell carcinoma.

\section{Materials and methods}

Patient population. The institutional review board approved this prospective study and informed consent was obtained from each participant. Thirty-one consecutive patients with advanced esophageal squamous cell carcinoma who underwent 
CRT at Chiba University Hospital from March 2004 to June 2006 were enrolled in this study. The subjects included 30 men and one woman, with a mean age of 65.8 (range 49 to 80) years. The diagnosis of squamous cell carcinoma of the esophagus was histologically confirmed from biopsy specimens obtained before CRT. Moreover, the patient eligibility criteria included the following; (i) age limit of 80 years and Karnofsky performance status of $70 \%$ or greater; (ii) white blood cell count $>4000$ cells $/ \mathrm{mm}^{3}$, haemoglobin $>10 \mathrm{~g}$, platelet count $>100000 / \mathrm{mm}^{3}$ and creatinine $<1.5 \mathrm{mg} / \mathrm{dl}$.

Treatment plan. The chemotherapy schedule consisted of cisplatin $15 \mathrm{mg} / \mathrm{m}^{2} /$ day by intravenous administration and 5-fluorouracil (5FU) $500 \mathrm{mg} / \mathrm{m}^{2} /$ day by continuous intravenous infusion for 5 days. A radiotherapy dose of 2 Gy per day was initiated on day 1 of chemotherapy and continued daily for 5 days a week for 4 weeks, totalling $40 \mathrm{~Gy}$. The target was the entire esophagus as well as the supraclavicular lymph nodes for upper and middle-third lesions. Of the 31 patients, 21 were treated with an additional 20 Gy of radiotherapy (to be a definitive CRT) and 10 were treated by transthoracic esophagectomy. Resection of the esophagus and proximal stomach was performed by a combined right thoracic abdominal and cervical approach. Resection included excision of the para-esophageal, para-carcial, left gastric and celiac lymph nodes.

Definition of response to treatment. Re-evaluation of the primary tumor was performed by CT, endoscopy and gastrography 3 to 4 weeks after the completion of CRT. EUS and PET were not used for response evaluation. The response to treatment was evaluated according to the General Rules for Esophageal Cancer proposed by the Japanese Society for Esophageal Disease and was categorized as either a complete response, partial response, stable disease, or progressive disease (18). This evaluation was based on a comparison of pre-CRT and post-CRT imaging study findings. Complete response was defined as the disappearance of all signs and symptoms of the tumor. Partial response was defined as a $\geq 50 \%$ decrease in tumor volume. Stable disease was defined as a $<50 \%$ decrease or $<25 \%$ increase in tumor volume. Progressive disease was defined as no significant change in tumor mass or a $>25 \%$ increase in tumor volume. However, one patient whose esophageal stenosis was so high that passage of barium and endoscopy were impossible was evaluated according to the improvement of degree of stenosis. Patients who showed a response, complete or partial, were categorized as clinical responders. The remaining patients with either stable or progressive disease were categorized as clinical non-responders.

Imaging studies. Perfusion CT was performed using a 16section multi-detector row CT scanner (Light Speed Ultra; GE Medical Systems, Milwaukee, WI). First, CT scanning was performed without an oral or intravenous contrast medium to localize the tumor. The tumor was localized in the nonenhanced CT scan and four adjacent 5-mm sections were selected at the level of the tumor for cine imaging. A dynamic study of this area was performed at a static table position during intravenous rapid bolus injection $(5 \mathrm{ml} / \mathrm{sec})$ of $40 \mathrm{ml}$
Table I. Patient characteristics.

\begin{tabular}{lc}
\hline Characteristic & No. \\
\hline Location & \\
Upper/Middle/Lower & $13 / 13 / 5$ \\
T stage & \\
T3/T4 & $7 / 24$ \\
N stage & \\
N0/N1 & $3 / 28$ \\
\hline
\end{tabular}

iomeprol containing $300 \mathrm{mg}$ iodine per $\mathrm{ml}$ (Iomeron 300; Bracco, Milan, Italy). The following parameters were used: 1-second gantry rotation time, $120 \mathrm{kV}, 60 \mathrm{~mA}, 5$-sec scanning delay from the start of injection, 40-sec duration of transverse data acquisition (four sections per gantry rotation) with breath holding and 5-mm reconstructed section thickness. The Perfusion data were transferred to an image processing workstation (Advantage Workstation 4.1; GE Medical Systems) and then were analyzed using a software (CT Perfusion 3.0; GE Medical Systems), based on the deconvolution method. The parameters generated by the software were blood flow (in $\mathrm{ml}$ per $100 \mathrm{~g}$ of wet tissue per $\mathrm{min}$ ), the blood volume (in $\mathrm{ml}$ per $100 \mathrm{~g}$ of wet tissue), the mean transit time (in sec) and the permeability surface area product (in $\mathrm{ml}$ per $100 \mathrm{~g}$ of wet tissue per min). For the derivation of functional maps of these Perfusion parameters, the arterial input curve of the contrast medium concentration is required and we obtained this arterial input curve from a ROI in the aorta. If the tumor was so high that we could not obtain a ROI of the aorta, we obtained the arterial input curve from a ROI in the carotid artery. The ROI was drawn freehand incorporating as much of the solid portion of the tumor as possible and omitting the necrotic areas by two gastrointestinal radiologists who did not know any information other than the tumor location and the mean of the Perfusion parameter was calculated. Care was taken to avoid encroaching on tumor boundaries, in order to exclude peritumoral hyperemia.

After the completion of Perfusion CT, $100 \mathrm{ml}$ of intravenous contrast was administered at $3 \mathrm{ml} / \mathrm{s}$ and a routine CT scan of the thorax and upper abdomen was obtained using $1.25-\mathrm{mm}$ contiguous sections (delay of $60 \mathrm{sec}, 120 \mathrm{kV}, 180$ $\mathrm{mA}, 0.5$-sec gantry rotation). These images were sent to the workstation and the maximum tumor wall thickness was measured in the axial plane at the same height for pre-CRT and post-CRT comparison by one gastrointestinal radiologist who was unaware of any clinical information concerning the patients.

Statistical analysis. The Perfusion parameters before CRT were compared between clinical responders and nonresponders and we compared pre-CRT Perfusion parameters with the contraction rate of the maximum tumor wall thickness. Statistical analysis was performed with MannWhitney $U$ test for comparisons of the two data sets and Spearman-rank correlations were used to assess the 


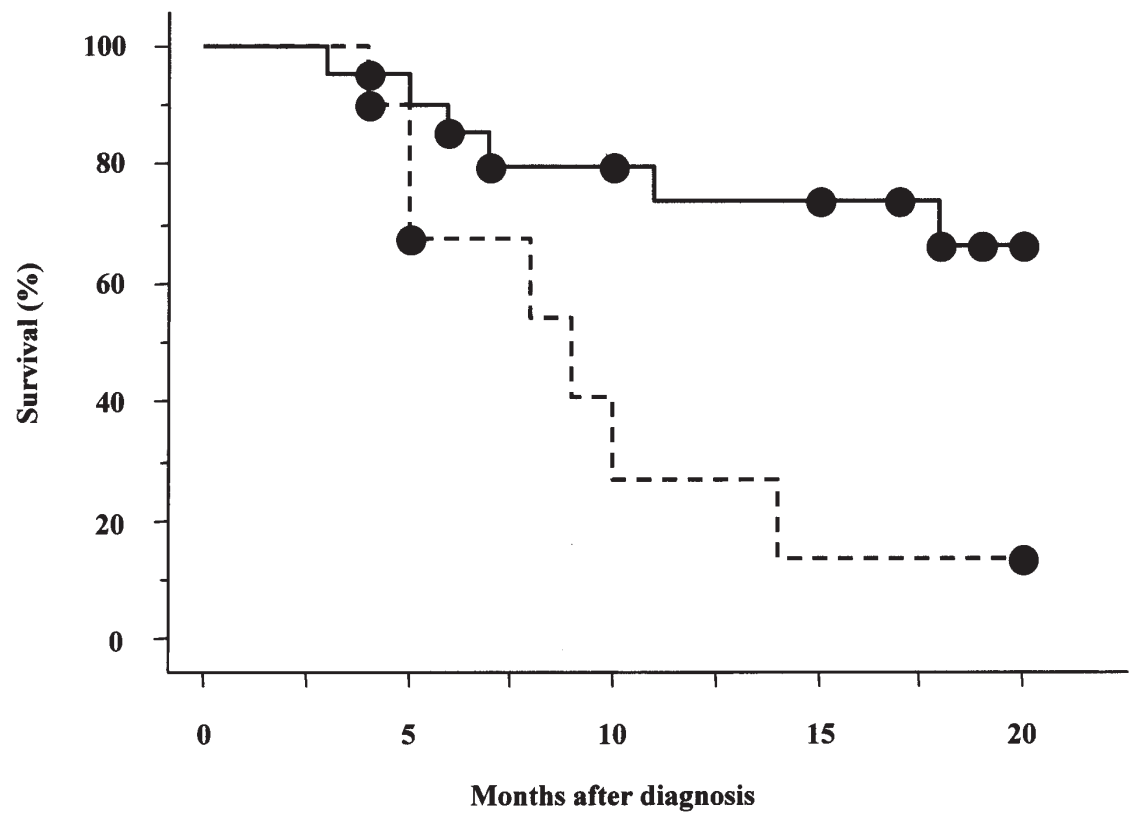

Responders $\quad---$ Non-responders Censored patients

Figure 1. Kaplan-Meier survival according to treatment response. The survival of the responder group was significantly better than that of the non-responder group $(\mathrm{P}=0.007)$.

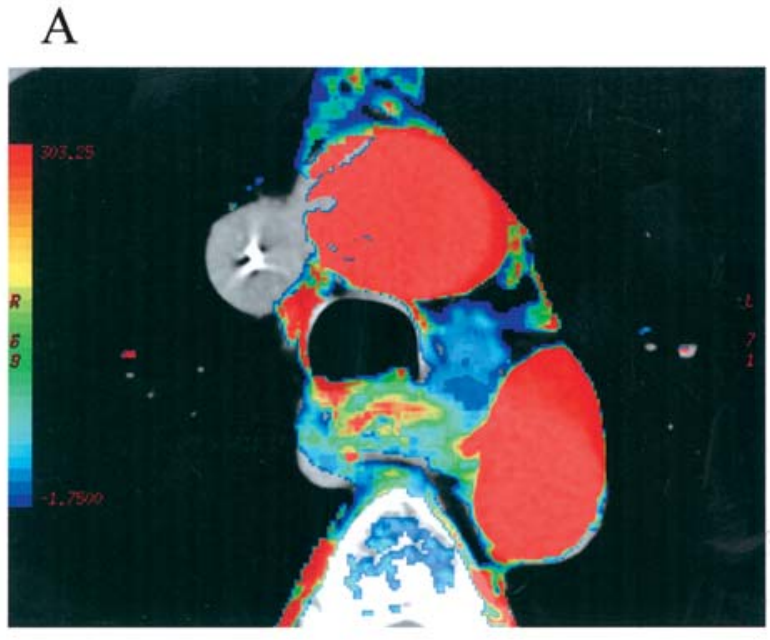

B

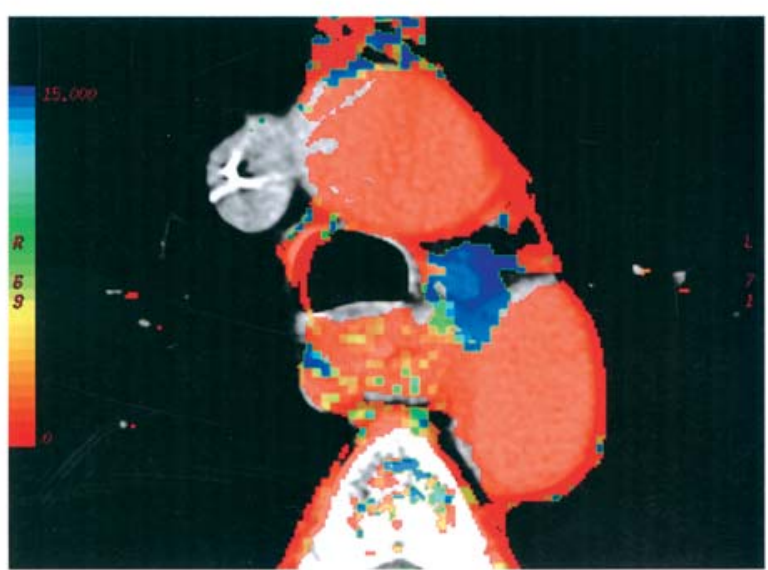

C

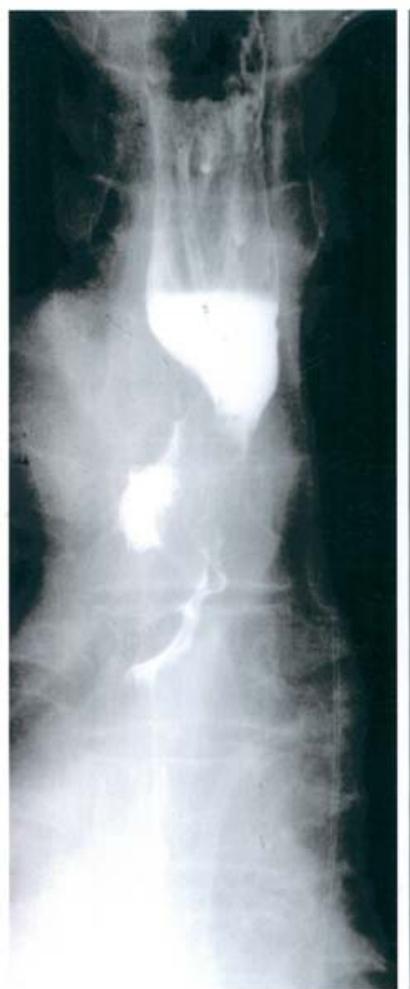

Pre-CRT

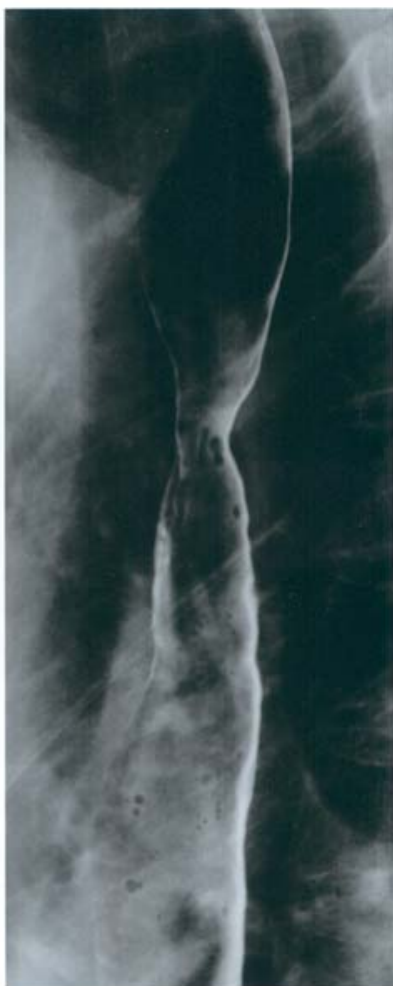

Post-CRT

Figure 2. (A) The tumor showed high blood flow (102 ml/100 mg/min) before CRT. (B) The tumor showed a short mean transit time (2.8 sec) before CRT. (C) The clinical response of the tumor to CRT was categorized as responder. 
A

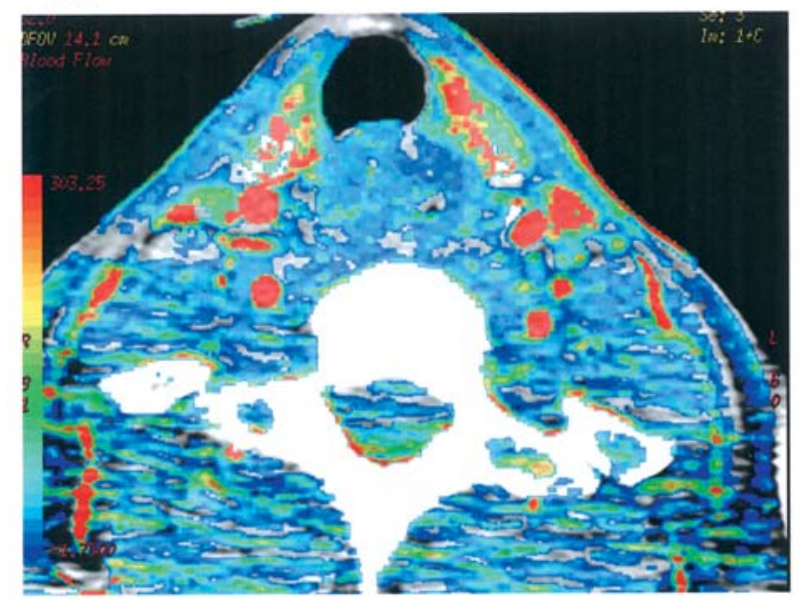

B

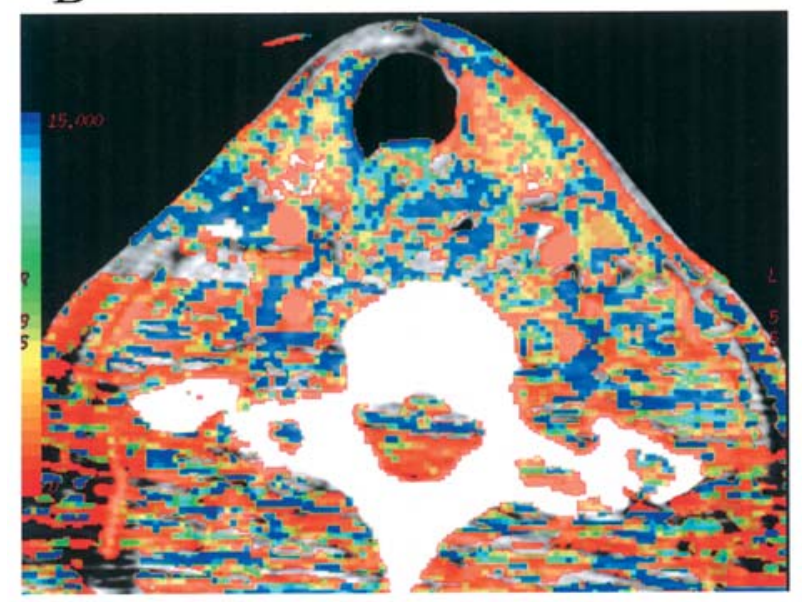

C

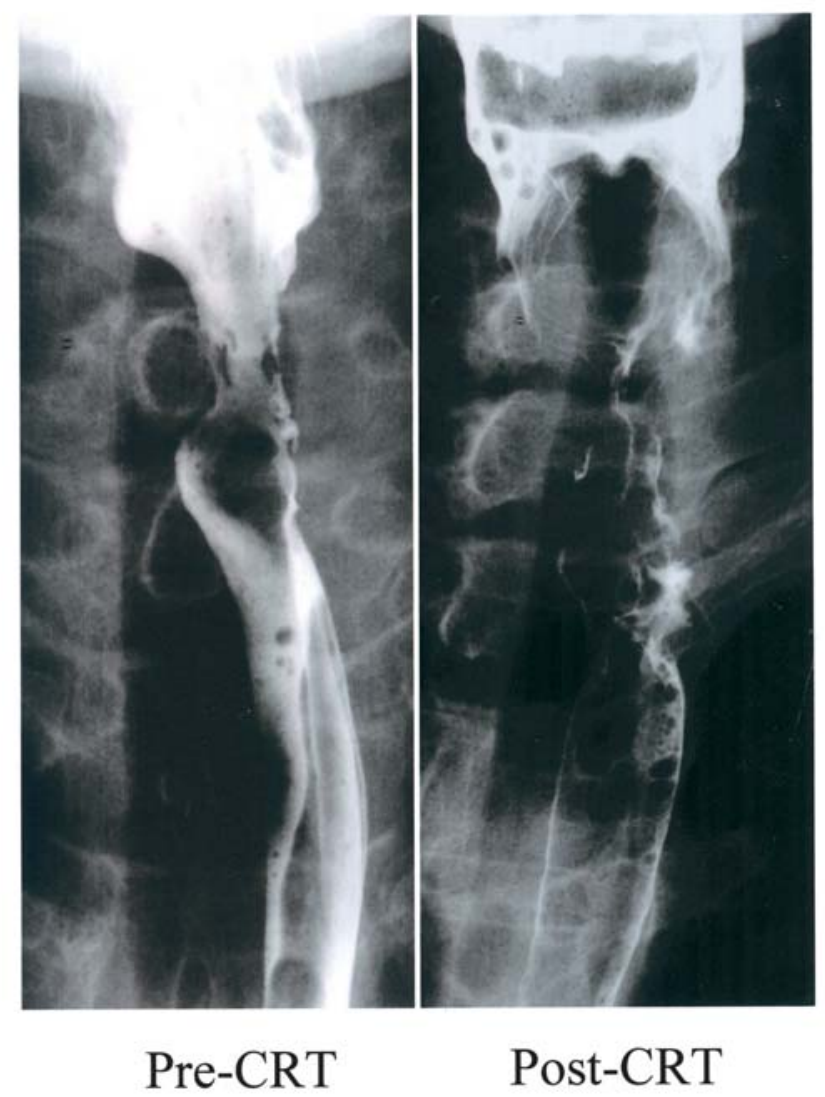

Figure 3. (A) The tumor showed low blood flow (32 ml/100 mg/min) before CRT. (B) The tumor showed a long mean transit time (12.1 sec) before CRT. (C) The clinical response of the tumor to CRT was categorized as non-responder.

relationship between Perfusion parameters and the tumor contraction rate. Univariate analysis for survival was performed using the log-rank test. The influence of blood flow and clinicopathological variables on survival was assessed by Cox's proportional hazards model. Survival curves were calculated by the Kaplan-Meier method. P-values were calculated for each comparison. $\mathrm{P}<0.05$ was considered to indicate a statistically significant difference.

\section{Results}

Thirty-one consecutive patients underwent CRT. Their characteristics are listed in Table I. T stage and N stage, according to UICC, were determined by CT/EUS.

Response to treatment and prognosis. Overall responses, such as complete and partial responses, were observed in 21 patients $(68 \%)$, with no response in the remaining 10 patients $(32 \%)$. The survival of the responder group was significantly better than that of the non-responder group $(\mathrm{P}=0.007)$ (Fig. 1).

Pre-CRT Perfusion parameters: clinical responders versus non-responders. There were significant differences in pre-CRT blood flow ( $\mathrm{P}=0.0004)$, pre-CRT mean transit time $(\mathrm{P}=0.002)$, and pre-CRT blood volume $(\mathrm{P}=0.03)$ between clinical responders and non-responders. Patients who had tumors with a high initial blood flow, a short initial mean transit time, or a high initial blood volume, showed a good response to CRT initial blood flow (Fig. 2), a long initial mean transit time, or a low initial blood volume, showed a poor response to CRT (Fig. 3). Permeability surface area product, however, did not show a statistically significant difference (Table II).

Correlation between pre-CRT Perfusion parameters and contraction rate of tumor wall thickness. We investigated the correlation between pre-CRT Perfusion parameters and the contraction rate of the maximum wall thickness of the tumor. The tumor contraction rate showed a significant correlation with blood flow $(\mathrm{r}=0.53, \mathrm{P}=0.003)$ and mean transit time ( $\mathrm{r}=-0.48, \mathrm{P}=0.009$ ) (Fig. 4), but no relationship with blood volume $(\mathrm{r}=0.31, \mathrm{P}=0.10)$ or permeability surface area product $(\mathrm{r}=-0.05, \mathrm{P}=0.79)$.

Prediction of the response to CRT by pre-CRT blood flow. There was a highly significant difference in pre-CRT blood flow between clinical responders and non-responders (Fig. 5). For pre-CRT blood flow, when the cut-off point was set at 
Table II. Perfusion parameters in clinical responders and non-responders.

\begin{tabular}{lccc}
\hline Perfusion parameter & Responders & Non-responders & P \\
\hline Blood flow (ml/100g/min) & $90.17 \pm 49.5$ & $35.91 \pm 14.73$ & 0.0004 \\
Blood volume (ml/100g) & $5.82 \pm 2.97$ & $4.00 \pm 1.32$ & 0.03 \\
Mean transit time (sec) & $7.38 \pm 3.71$ & $12.3 \pm 4.5$ & 0.002 \\
Permeability-surface area product $(\mathrm{ml} / 100 \mathrm{~g} / \mathrm{min})$ & $12.29 \pm 6.55$ & $11.47 \pm 3.15$ & 0.87 \\
\hline
\end{tabular}

A

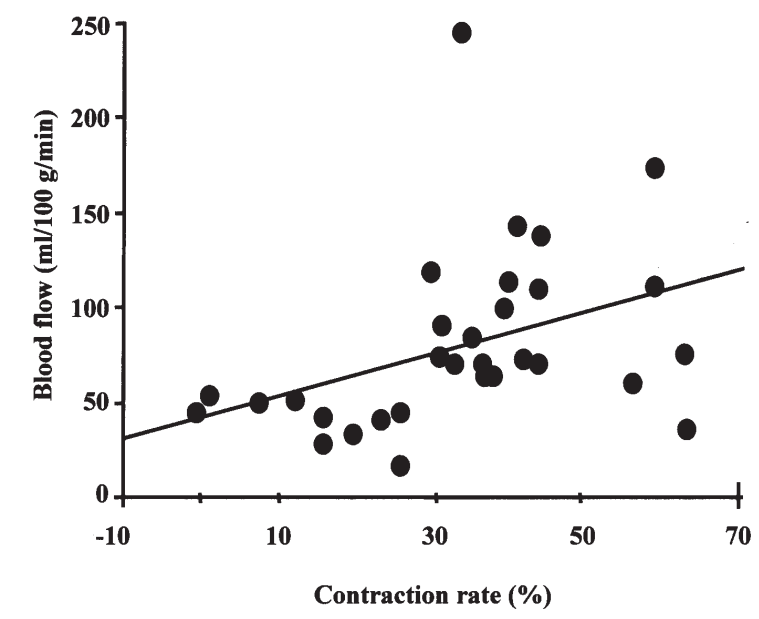

B

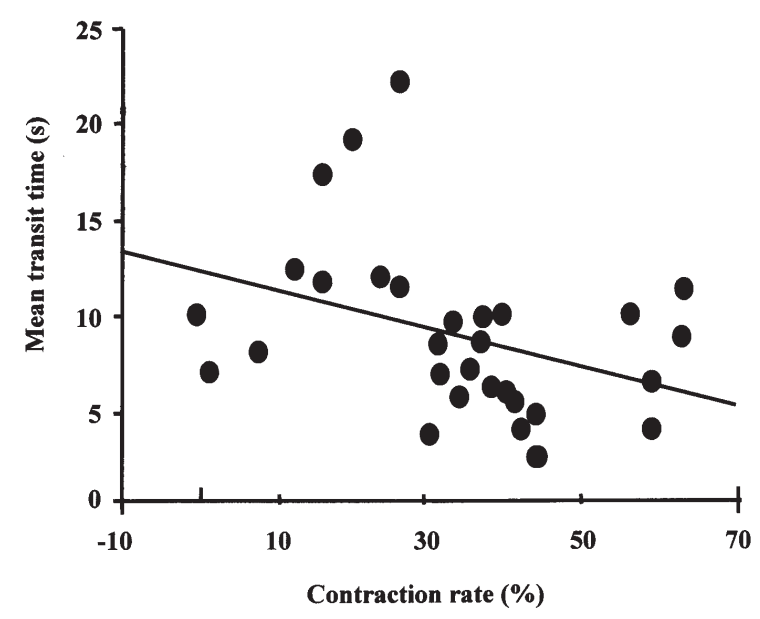

Figure 4. Tumor contraction rate was significantly correlated with blood flow $(\mathrm{P}=0.003)(\mathrm{A})$ and mean transit time $(\mathrm{P}=0.009)(\mathrm{B})$.

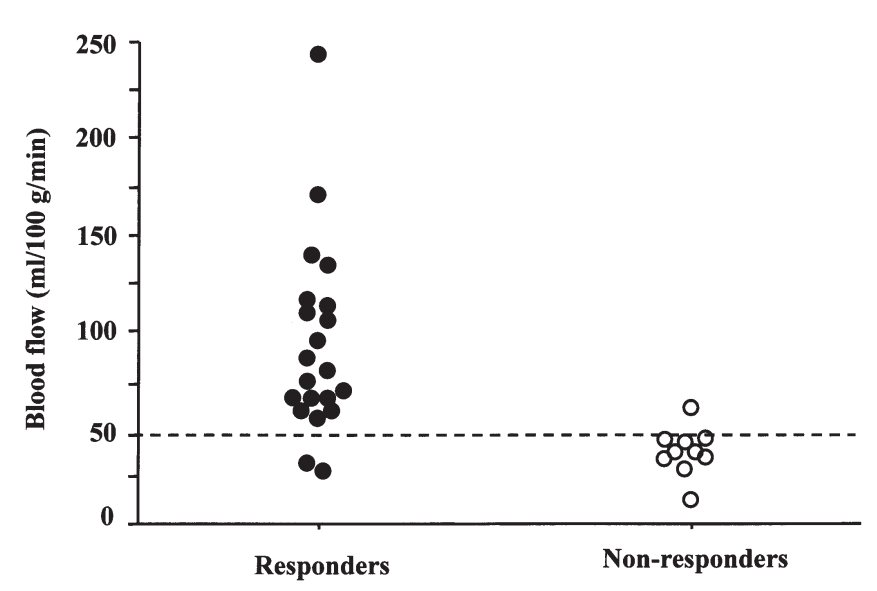

Figure 5. There were significant differences in pre-CRT blood flow $(\mathrm{P}=0.0004)$.

$50 \mathrm{ml} / 100 \mathrm{~g} / \mathrm{min}$, accuracy was $90.3 \%$, sensitivity was $90.5 \%$ and specificity was $90.0 \%$ for the detection of clinical responders (Table III).

Prognostic relevance and multivariate analysis. Using univariate analysis, blood flow showed a significant association with survival $(\mathrm{P}=0.006)$ (Table IV). The association of other clinicopathological factors, such as age, tumor location, $\mathrm{T}$ stage, $\mathrm{N}$ stage, tumor size and treatment were negligible. To
Table III. Prediction of clinical response to CRT.

\begin{tabular}{lcc}
\hline & Responders & Non-responders \\
\hline Blood flow $\geq 50 \mathrm{ml} / 100 \mathrm{~g} / \mathrm{min}$ & 19 & 1 \\
Blood flow $<50 \mathrm{ml} / 100 \mathrm{~g} / \mathrm{min}$ & 2 & 9 \\
\hline
\end{tabular}

determine the independent prognostic value of various parameters for patients' survival, a Cox's regression model was constructed using blood flow, $\mathrm{T}$ stage, $\mathrm{N}$ stage and tumor size (Table V). As a result, blood flow was an independent prognostic factor $(\mathrm{P}=0.01$; hazards ratio, 6.18 ; $95 \% \mathrm{CI}, 1.48$ 23.68). Fig. 6 shows survival curves according to blood flow by Kaplan-Meier analysis. Patients with high blood flow ( $\geq 50 \mathrm{ml} / 100 \mathrm{~g} / \mathrm{min}$ ) tumors survived significantly longer than those with low blood flow ( $<50 \mathrm{ml} / 100 \mathrm{~g} / \mathrm{min})$ tumors $(\mathrm{P}=0.006)$.

\section{Discussion}

Recently, the effectiveness of CRT for locally advanced esophageal squamous cell carcinoma has become clear. Stahl et al $(19,20)$ reported that the overall survival rate was significantly higher in clinical responders than in nonresponders and that preoperative CRT improved local progression-free survival. Therefore, CRT is expected to serve 


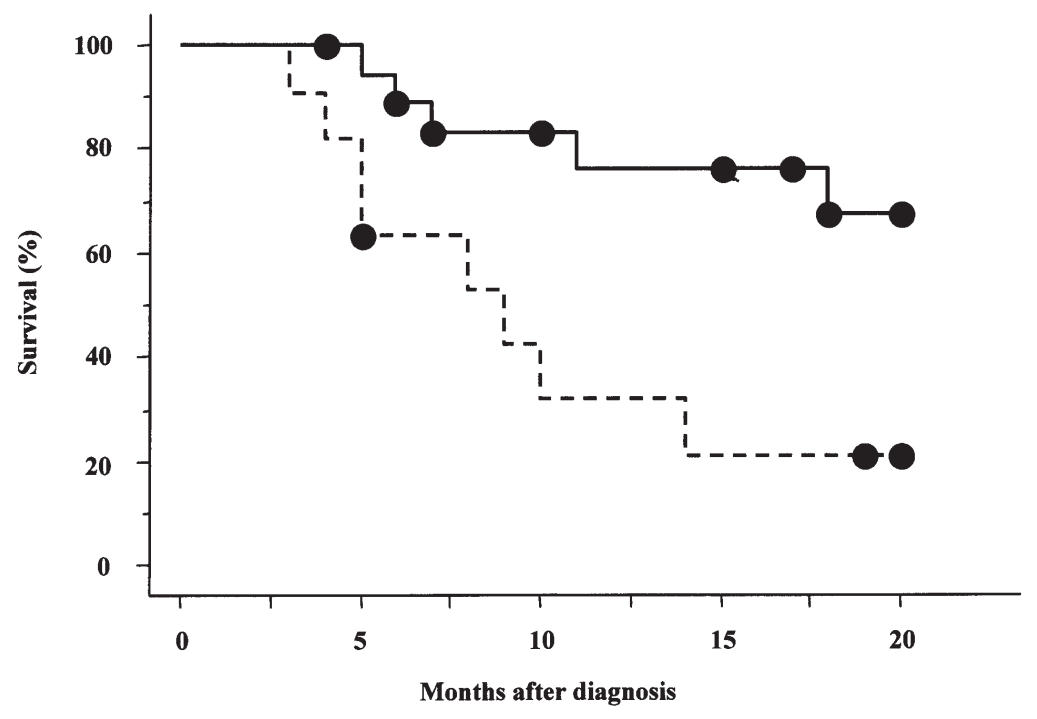

— Blood flow $\geq 50 \quad--$ Blood flow $<50$ Censored patients

Figure 6. Kaplan-Meier survival according to blood flow. Survival was significantly better in the high blood flow group than in the low blood flow group $(\mathrm{P}=0.006)$.

Table IV. Univariate analysis of pre-CRT blood flow and clinicopathological factors in survival of 31 patients treated with CRT.

\begin{tabular}{|c|c|c|c|c|}
\hline Variables & & No. & MST (months) & $\mathrm{P}$ \\
\hline \multirow[t]{2}{*}{ Blood flow } & $<50 \mathrm{ml} / 100 \mathrm{~g} / \mathrm{min}$ & 11 & 9.0 & 0.006 \\
\hline & $\geq 50 \mathrm{ml} / 100 \mathrm{~g} / \mathrm{min}$ & 20 & & \\
\hline \multirow[t]{2}{*}{ Age } & $<65$ years & 14 & & 0.99 \\
\hline & $\geq 65$ years & 17 & & \\
\hline \multirow[t]{2}{*}{ Location } & Upper & 13 & & 0.71 \\
\hline & Middle or lower & 18 & 18.0 & \\
\hline \multirow[t]{2}{*}{ T stage } & $\mathrm{T} 3$ & 7 & & 0.71 \\
\hline & $\mathrm{T} 4$ & 24 & 18.0 & \\
\hline \multirow[t]{2}{*}{$\mathrm{N}$ stage } & NO & 3 & 6.0 & 0.95 \\
\hline & N1 & 28 & 18.0 & \\
\hline \multirow[t]{2}{*}{ Tumor size } & $<80 \mathrm{~mm}$ & 21 & 18.0 & 0.85 \\
\hline & $\geq 80 \mathrm{~mm}$ & 10 & & \\
\hline \multirow[t]{2}{*}{ Treatment } & CRT + surgery & 10 & 14.0 & 0.26 \\
\hline & CRT & 21 & & \\
\hline
\end{tabular}

as a means of further improving the therapeutic results in advanced esophageal cancer. On the other hand, CRT has many adverse effects such as bone marrow suppression and esophagitis. In markedly effective cases, the merits of CRT are great, but in ineffective cases, the cancer may progress during the treatment period. Thus, reliable markers that can predict the response to CRT are needed. Previous studies have implicated various molecules as potential candidates for markers of the CRT response in human esophageal cancer, such as p53, CDC25B, metallothionein, vascular endothelial cell growth factor and microvessel density (21-24). These were all based on pathological analyses and there has been no analysis using CT as a CRT response marker to date.

Axel (8) first described a method of assessing tissue Perfusion using dynamic contrast-enhanced CT. Because of the technical limitations of early CT scanners, this method was not widely available. However, with the advent of spiral CT and multi-detector row CT scanners, the technique has become widely popular and new indications have emerged.

In the present study, we examined the usefulness of Perfusion CT in patients with esophageal squamous cell carcinoma who received CRT. Our study demonstrated that 
Table V. Multivariate analysis of pre-CRT blood flow and clinicopathological factors in survival of 31 patients treated with CRT.

\begin{tabular}{lcccc}
\hline Variables & Category & Hazard ratio & $95 \%$ CI & P \\
\hline Blood flow & $<50 \mathrm{vs.} \geq 50 \mathrm{ml} / 100 \mathrm{~g} / \mathrm{min}$ & 6.18 & $1.48-23.68$ & 0.01 \\
T stage & $\mathrm{T} 3 \mathrm{vs} . \mathrm{T} 4$ & 1.44 & $0.34-5.64$ & 0.62 \\
N stage & $\mathrm{N} 0 \mathrm{vs} . \mathrm{N} 1$ & 2.73 & $0.27-27.58$ & 0.40 \\
Tumor size & $<80 \mathrm{~mm}$ vs. $\geq 80 \mathrm{~mm}$ & 0.62 & $0.14-2.61$ & 0.51 \\
Location & Upper vs. Middle or lower & 0.69 & $0.22-2.16$ & 0.52 \\
\hline
\end{tabular}

tumors with a higher blood flow, a higher blood volume, or a shorter mean transit time at pre-CRT might show a better clinical response to CRT. For pre-CRT blood flow, accuracy was $90.3 \%$ for detection of clinical responders if the cut-off point was set at $50 \mathrm{ml} / 100 \mathrm{~g} / \mathrm{min}$. We found that patients with high blood flow tumors survived significantly longer than those with low blood flow tumors. In head and neck cancer, Hermans et al (25) reported similar findings and concluded that a low Perfusion rate predicted a poor response to radiotherapy, based on dynamic CT study. In oropharyngeal squamous cell carcinoma, Gandhi et al (26) demonstrated that a higher blood volume before chemotherapy showed a significant correlation with a better endoscopic tumor response, using Perfusion CT. We assume that these results are concerned with the tissue oxygen status and tumor microcirculation. Basically, the tissue oxygen status has been demonstrated to be a very important factor determining radiosensitivity both in vitro and in vivo $(27,28)$. Oxygen delivery to tumor tissues appears to rely on a network of microvessels, based on in vivo observations of vascular geometry and blood flow in the tumor microcirculation. It is well known that oxygen gradients exist in the microcirculation, and it is further hypothesized that microvascular pathways with a higher flow have higher oxygen content (29). Also, Hemphill et al (30) reported that Perfusion CT assessment of ROI surrounding an oxygen probe in the intraparenchymal brain tissue showed a significant correlation between local brain tissue oxygen tension and mean transit time, that is, intraparenchymal brain tissue oxygen tension was negatively and significantly correlated with mean transit time. On the other hand, the tumor microcirculation is clearly an important factor in drug delivery to cancer cells and the efficacy of drug delivery can be high in highly vascularized tumors. Thus, Perfusion CT has the potential to reflect the microvessel density and the tissue oxygen status and we assume that these data support our present observation that Perfusion parameters will be favorable predictive and prognostic factors in patients who have undergone CRT.

$\mathrm{CT}$ is the most common modality for evaluating cancer patients. We showed the possibility that Perfusion CT could predict the response to CRT in esophageal squamous cell carcinoma before CRT. In the near future, we may be able to determine who should undergo surgery without CRT and who should undergo CRT before surgery, using Perfusion CT. However, to obtain more conclusive results, a larger patient population should be studied. Nevertheless, we hope that our results will provide an important insight into selecting the optimal therapeutic strategy for the treatment of esophageal squamous cell carcinoma.

\section{Acknowledgements}

This study was supported in part by a 21 st Century Center of Excellence (COE) Programs Grant from the Ministry of Education, Culture, Sports, Science and Technology of Japan.

\section{References}

1. Smith TJ, Ryan LM, Douglass HO Jr, Haller DG, Dayal Y, Kirkwood J, Tormey DC, Schutt AJ, Hinson J and Sischy B: Combined chemoradiotherapy vs. radiotherapy alone for early stage squamous cell carcinoma of the esophagus: a study of the Eastern Cooperative Oncology Group. Int J Radiat Oncol Biol Phys 42: 269-276, 1998.

2. Cooper JS, Guo MD, Herskovic A, Macdonald JS, Martenson JA Jr, Al-Sarraf M, Byhardt R, Russell AH, Beitler JJ, Spencer S, Asbell SO, Graham MV and Leichman LL: Chemoradiotherapy of locally advanced esophageal cancer: long-term follow-up of a prospective randomized trial (RTOG 85-01). Radiation Therapy Oncology Group. JAMA 281: 1623-1627, 1999.

3. Poplin EA, Jacobson J, Herskovic A, Panella TJ, Valdivieso M, Hutchins LF and Macdonald JS: Evaluation of multimodality treatment of locoregional esophageal carcinoma by Southwest Oncology Group 9060. Cancer 78: 1851-1856, 1996.

4. Ancona E, Ruol A, Castoro C, Chiarion-Sileni V, Merigliano S, Santi S, Bonavina L and Peracchia A: First-line chemotherapy improves the resection rate and long-term survival of locally advanced (T4, any N, M0) squamous cell carcinoma of the thoracic esophagus: final report on 163 consecutive patients with 5-year follow-up. Ann Surg 226: 714-724, 1997.

5. Stahl M, Wilke H, Fink U, Stuschke M, Walz MK, Siewert JR, Molls M, Fett W, Makoski HB, Breuer N, Schmidt U, Niebel W, Sack H, Eigler FW and Seeber S: Combined preoperative chemotherapy and radiotherapy in patients with locally advanced esophageal cancer. Interim analysis of a phase II trial. J Clin Oncol 14: 829-837, 1996.

6. Shimada H, Hoshino T, Okazumi S, Matsubara H, Funami Y, Nabeya Y, Hayashi H, Takeda A, Shiratori T, Uno T, Ito H and Ochiai T: Expression of angiogenic factors predicts response to chemoradiotherapy and prognosis of oesophageal squamous cell carcinoma. Br J Cancer 86: 552-557, 2002.

7. Axel L: Cerebral blood flow determination by rapid-sequence computed tomography: theoretical analysis. Radiology 137: 679-686, 1980.

8. Axel L: Tissue mean transit time from dynamic computed tomography by a simple deconvolution technique. Invest Radiol 18: 94-99, 1983.

9. Miles KA: Measurement of tissue perfusion by dynamic computed tomography. Br J Radiol 64: 409-412, 1991.

10. Blomley MJ, Coulden R, Bufkin C, Lipton MJ and Dawson P: Contrast bolus dynamic computed tomography for the measurement of solid organ perfusion. Invest Radiol 28 (Suppl 5): S72-S78, 1993. 
11. Dawson $\mathrm{P}$ and Blomley MJ: Contrast media as extracellular fluid space markers: adaptation of the central volume theorem. $\mathrm{Br} \mathrm{J}$ Radiol 69: 717-722, 1996.

12. St Lawrence KS and Lee TY: An adiabatic approximation to the tissue homogeneity model for water exchange in the brain: II. Experimental validation. J Cereb Blood Flow Metab 18: 1378-1385, 1998.

13. Cenic A, Nabavi DG, Craen RA, Gelb AW and Lee TY: Dynamic CT measurement of cerebral blood flow: a validation study. AJNR Am J Neuroradiol 20: 63-73, 1999.

14. Cenic A, Nabavi DG, Craen RA, Gelb AW and Lee TY: A CT method to measure hemodynamics in brain tumors: validation and application of cerebral blood flow maps. AJNR Am J Neuroradiol 21: 462-470, 2000.

15. Vaupel P, Kallinowski F and Okunieff P: Blood flow, oxygen and nutrient supply and metabolic microenvironment of human tumors: a review. Cancer Res 49: 6449-6465, 1989.

16. Baillie CT, Winslet MC and Bradley NJ: Tumor vasculature-a potential therapeutic target. Br J Cancer 72: 257-267, 1995.

17. Jain RK: Determinants of tumor blood flow: a review. Cancer Res 48: 2641-2658, 1988.

18. The Japanese Society for Esophageal Disease: Guidelines for the Clinical and Pathologic Studies on Carcinoma of the Esophagus. Isono K (ed). $9^{\text {th }}$ edition. Kanehara Shuppan, Tokyo, 1999.

19. Stahl M, Wilke H, Stuschke M, Walz MK, Fink U, Molls M, Siewert JR, Schroeder M, Makoski HB, Schmidt U, Seeber S and Vanhoefer U: Clinical response to induction chemotherapy predicts local control and long-term survival in multimodal treatment of patients with locally advanced esophageal cancer. J Cancer Res Clin Oncol 131: 67-72, 2005.

20. Stahl M, Stuschke M, Lehmann N, Meyer HJ, Walz MK, Seeber S, Klump B, Budach W, Teichmann R, Schmitt M, Schmitt G, Franke C and Wike H: Chemoradiation with and without surgery in patients with locally advanced squamous cell carcinoma of the esophagus. J Clin Oncol 23: 2310-2317, 2005.

21. Berger AC, Farma J, Scott WJ, Freedman G, Weiner L, Cheng JD, Wang $\mathrm{H}$ and Goldberg $\mathrm{M}$ : Complete response to neoadjuvant chemoradiotherapy in esophageal carcinoma is associated with significantly improved survival. J Clin Oncol 23: 4330-4337, 2005.
22. Miyata H, Doki Y, Shiozaki H, Inoue M, Yano M, Fujiwara Y, Yamamoto H, Nishioka K, Kishi K and Monden M: CDC25B and p53 are independently implicated in radiation sensitivity for human esophageal cancers. Clin Cancer Res 6: 4859-4865, 2000.

23. Yamamoto M, Tsujinaka T, Shiozaki H, Doki Y, Tamura S, Inoue $\mathrm{M}$, Hirano $\mathbf{M}$ and Monden $\mathrm{M}$ : Metallothionein expression correlates with the pathological response of patients with esophageal cancer undergoing preoperative chemoradiation therapy. Oncology 56: 332-337, 1999.

24. Hironaka S, Hasebe T, Kamijo T, Ohtsu A, Boku N, Yoshida S, Saitoh $\mathrm{H}$ and Ochiai A: Biopsy specimen microvessel density is a useful prognostic marker in patients with $\mathrm{T}(2-4) \mathrm{M}(0)$ esophageal cancer treated with chemoradiotherapy. Clin Cancer Res 8: 124-130, 2002.

25. Hermans R, Meijerink M, Van den Bogaert W, Rijinders A, Weltens C, Lambin P: Tumor perfusion rate determined noninvasively by dynamic computed tomography predicts outcome in head-and-neck cancer after radiotherapy. Int J Radiat Oncol Biol Phys 57: 1351-1356, 2003.

26. Gandhi D, Chepeha DB, Miller T, Carlos RC, Bradford CR, Karamchandani R, Worden F, Eisbruch A, Teknos TN, Wolf GT and Mukherji SK: Correlation between initial and early follow-up CT Perfusion Parameters with endoscopic tumor response in patients with advanced squamous cell carcinomas of the oropharynx treated with organ-preservation therapy. AJNR Am J Neuroradiol 27: 101-106, 2006.

27. Moulder JE and Rockwell S: Tumor hypoxia: its impact on cancer therapy. Cancer Metastasis Rev 5: 313-341, 1987.

28. Rockwell S and Moulder JE: Hypoxic fractions of human tumors xenografted into mice: a review. Int J Radiat Oncol Biol Phys 19: 197-202, 1990.

29. Tsai AG, Johnson PC and Intaglietta M: Oxygen gradients in the microcirculation. Physiol Rev 83: 933-963, 2003.

30. Hemphill JC 3rd, Smith WS, Sonne DC, Morabito D and Manley GT: Relationship between brain tissue oxygen tension and CT perfusion: feasibility and initial results. AJNR Am J Neuroradiol 26: 1095-1100, 2005. 